\title{
Case Report on Acute Psychosis Due to Anti-NMDAR Encephalitis
}

\author{
Shabana Ahamed, Harin Karunajeewa \\ Western Health, Melbourne, Australia \\ Email: shab_ahamed@yahoo.com
}

Received 11 October 2013; revised 11 December 2013; accepted 7 January 2014

Copyright (C) 2014 by authors and Scientific Research Publishing Inc.

This work is licensed under the Creative Commons Attribution International License (CC BY). http://creativecommons.org/licenses/by/4.0/

(c) (i) Open Access

\begin{abstract}
A 32-year-old female with depression on treatment, was presented with acute psychosis, behavioural symptoms, autonomic instability and a prodromal illness. This occurred on a background of a strong family history of schizophrenia. Despite escalating doses of anti-psychotics, she failed to improve. Her CSF showed a lymphocytic pleocytosis and confirmed the presence of anti-NMDAR antibodies. Following treatment with immunotherapy and excision of her underlying ovarian tumour, she showed a dramatic and seemingly full recovery of her psychotic symptoms. She was weaned off all medications with no residual symptoms. Clinician awareness is important to treat this uncommon but potentially reversible condition.
\end{abstract}

\section{Keywords}

Psychosis; Ovarian Teratoma; Encephalitis

\section{Case Presentation}

A 32-year old woman with a previous history of depression and strong family history of schizophrenia was presented to a rural hospital with a three-day history of confusion, insomnia, agitation, auditory and visual hallucinations. She was initially diagnosed with acute psychosis and treated with olanzapine, quetiapine, sodium valproate and clonazepam. Ten days prior to presentation, she had a prodromal viral like illness with headaches and arthralgias treated as migraine with no improvement.

This presentation was complicated by significant hemodynamic compromise (fever, hypotension and tachycardia), and she was transferred to our hospital due to concerns regarding neuroleptic malignant syndrome or an underlying meningo-encephalitic process.

On examination, she had a temperature of $38.6^{\circ} \mathrm{C}$, sinus tachycardia (pulse $\left.=130 \mathrm{~b} / \mathrm{min}\right)$, hypotension $(\mathrm{BP}=$ 95/65 mmHg) and hyperreflexia but no meningeal signs. She displayed florid psychotic symptoms—including 
hallucinations, paranoid ideation, violent agitation and restlessness. Baseline biochemistry was essentially normal except for an elevated creatinine kinase at $743 \mathrm{U} / \mathrm{L}(0-170)$. Other laboratory tests are shown in Table 1. Brain computer tomography (CT) and MRI were unremarkable. EEG revealed non-specific slowing of waves.

Lumbar puncture showed a lymphocytic pleocytosis with 0 polymorphs $\left(\times 10^{6} / \mathrm{L}\right)$, 49 lymphocytes $\left(\times 10^{6} / \mathrm{L}\right)$ and 49 monocytes $\left(\times 10^{6} / \mathrm{L}\right)$. The patient's glucose and protein levels were normal. At this stage, the patient was empirically started on ceftriaxone and acyclovir but treatment was discontinued when herpes simplex virus was negative by polymerase chain reaction (CSF). In view of the CSF findings, personality changes and autonomic instability, screening tests for auto-immune disorders, obscure infections, inflammatory, endocrine and paraneoplastic causes were done. These were unremarkable, with one exception: On day 10, results of Anti- $N$-methylD-aspartate receptor (NMDAR) antibodies testing showed that these had been detected in CSF. Although blood testing did not detect these antibodies in serum, based on the presumed high-sensitivity of CSF serology, a presumptive diagnosis of anti-NMDAR encephalitis was made.

The patient was commenced on intravenous immunoglobulin (IVIG) and pulse methylprednisolone (1 $\mathrm{g}$ daily for 5 days). Given the association between anti-NMDAR encephalitis and ovarian teratoma, imaging of ovaries was performed first with computer tomography followed by pelvic ultrasound. A 1.6 centimetre right ovarian mass was first believed to be a luteal cyst. However, over the next two weeks, her psychotic symptoms failed to improve despite escalating treatment with multiple anti-psychotics (olanzapine, valproate, clonazepam). Given the pre-test probability of underlying ovarian teratoma, a gynaecological decision was sought regarding the ovarian mass, leading to a complete excisional diagnostic biopsy of the right ovary on day 28. This revealed a grade 2 immature teratoma confirmed on histopathology. She was commenced on second-line therapy with Rituximab ( 4 courses in 4 weeks, $375 \mathrm{mg} / \mathrm{m}^{2}$ ) and cyclophosphamide (6 courses, $1 \mathrm{x} / 4$ weeks, $750 \mathrm{mg} / \mathrm{m}^{2}$ ).

She underwent cognitive rehabilitation for a period of three weeks before returning home. On discharge, she demonstrated aspects of executive dysfunction including reduced generativity, concrete and lateral thinking tendencies with mild planning and organizational weakness. There was no evidence of frontal-behavioural dysfunction.

A month following discharge she showed dramatic and seemingly full recovery of psychotic symptoms. She had been weaned from all anti-psychotic/neuroleptic medications with no residual symptoms.

\section{Discussion}

Anti-NMDA-R encephalitis is a rare form of autoimmune encephalitis first described in 2007. Although the incidence is unknown, it is thought to be more frequent than any other paraneoplastic encephalitis [1]. This syndrome has been predominantly described in young females (81\%), although children as young as 2 years old have been reported in the literature [2]. This condition appears more frequently in Japanese individuals than in Caucasians [3], which may suggest a genetic predisposition. More studies are being done to assess the immunogenetics of such patients. This is interesting considering most tumours do not have racial bias [4].

NMDA-receptors are part of the central nervous system and are responsible for synaptic transmission and plasticity. There are two subtypes, NR1 and NR2, which bind to glycine and glutamate, respectively. The syndrome is characterized by IgG antibodies to the NR1 subunit of the NMDAR. An immune-mediated mechanism likely underlies this syndrome. It is thought that antibodies to tumour cells cross-react with NMDA-receptors leading to destruction or down-regulation. Similarly, triggers like viral infections have been described in other encephalitides.

The inhibition of NMDA receptors causes a reduction in gamma-aminobutyric acid (GABA) release in presynaptic neurons, which in turn, disinhibits excitatory pathways of postsynaptic glutamate release in the prefrontal or subcortical structures. This may be responsible for the development of psychosis, catatonia, rigidity and dyskinesias [1].

NMDAR are also found in dopaminergic, noradrenergic and cholinergic systems. This has further effects resulting into features of autonomic instability. The effect on the brainstem causes semi rhythmic movements in bulbar, limb, or trunk muscles, whereas the effect on the pontine-medullary respiratory network can result in breathing dysfunction and hypoventilation [1].

In our patient, psychosis and autonomic instability were present with other features absent.

Iizuka et al. [3] has previously described five clinical phases—prodromal, psychotic, unresponsive, hyperkinetic, and a gradual recovery phase. As seen in our patient, the prodromal phase is usually characterized by fever, headache or malaise, followed a few days later by mood and behavioural changes. The earliest symptoms are 
Table 1. Investigations.

\begin{tabular}{|c|c|c|c|}
\hline Haemoglobin & $14.2 \mathrm{~g} / \mathrm{dL}$ & Pregnancy Test & Negative \\
\hline Platelets & $131\left(\times 10^{9} / \mathrm{L}\right)$ & CK & $734 \mathrm{IU} / \mathrm{L}(<145)$ \\
\hline Neutrophils & $2.7\left(\times 10^{9} / \mathrm{L}\right)$ & Coagulation Profile & Normal \\
\hline Lymphocytes & $1.5\left(\times 10^{9} / \mathrm{L}\right)$ & Hepatitis B, C & Negative \\
\hline Blood film: & Normal morphology & HIV Serology & Negative \\
\hline Renal function & & Quantiferon Gold & Negative \\
\hline $\mathrm{Na}$ & 144 mmol/L(136 - 145) & Mycoplasma Serology & Negative \\
\hline $\mathrm{K}+$ & 3.5 mmol/L (3.5 - 5.0) & Mycoplasma PCR & Negative \\
\hline $\mathrm{Cl}-$ & 109 mmol/L (95 - 110) & Urine culture & No growth \\
\hline $\mathrm{HCO}_{3}-$ & $28 \mathrm{mmol} / \mathrm{L}(22-31)$ & Blood cultures & No growth \\
\hline Urea & 1.9 mmol/L (2.5 - 6.7) & & \\
\hline Creatinine & 53 umol/L (45 - 90) & Respiratory viral PCR & Negative \\
\hline eGFR & $>90$ & Mycobacteria PCR & Negative \\
\hline \multicolumn{4}{|l|}{ Liver function tests } \\
\hline Bilirubin & $7 \mathrm{umol} / \mathrm{L}(0-15)$ & Serum ceruloplasmin & $0.28 \mathrm{~g} / \mathrm{L}(0.15-0.30)$ \\
\hline ALT & $31 \mathrm{U} / \mathrm{L}(0-30)$ & Serum Purkinje Cell Antibody & Negative \\
\hline AST & $42 \mathrm{U} / \mathrm{L}(0-30)$ & Anti-Hu antibodies & Negative \\
\hline ALP & $50 \mathrm{U} / \mathrm{L}(20-105)$ & Anti-Yo antibodies & Negative \\
\hline GGT & $22 \mathrm{U} / \mathrm{L}(0-30)$ & Anti-NMDAR antibody (CSF) & Positive \\
\hline Total protein & $78 \mathrm{~g} / \mathrm{L}(65-85)$ & ACE level & $9.1 \mathrm{U} / \mathrm{L}(<48)$ \\
\hline \multirow[t]{2}{*}{ Albumin } & $38 \mathrm{~g} / \mathrm{dL}(38-50)$ & Rheumatoid Factor & $6 \mathrm{kIU} / \mathrm{L}(14)$ \\
\hline & & ANA & Negative \\
\hline CSF & & ANCA & Negative \\
\hline Polymorphs & $0\left(\times 10^{6} / \mathrm{L}\right)$ & & \\
\hline Lymphocytes & $49\left(\times 10^{6} / \mathrm{L}\right)$ & C-reactive protein (CRP) & $62 \mathrm{mg} / \mathrm{L}(<2)$ \\
\hline Monocytes & $49\left(\times 10^{6} / \mathrm{L}\right)$ & Lactate & $2.0 \mathrm{mmol} / \mathrm{L}(0.5-2.0)$ \\
\hline Appearance & Clear & & \\
\hline Glucose & 3.0 mmol/L (2.0 - 3.9) & CA19-9 & $<3 \mathrm{u} / \mathrm{mL}(<38)$ \\
\hline Protein & $0.23 \mathrm{~g} / \mathrm{L}(0.15-0.45)$ & CA 125 & $8 \mathrm{u} / \mathrm{mL}(<35)$ \\
\hline Viral PCR & Negative & Serum Alfa fetoprotein & $2 \mathrm{ug} / \mathrm{L}(<10)$ \\
\hline Culture & No growth & CEA & $<0.5$ ug/L (90 - 2.5) \\
\hline Gram Stain & Negative & CA 15-3 & $27 \mathrm{u} / \mathrm{mL}(0-31)$ \\
\hline Cryptococcal antigen & Negative & FT4 & $17.9 \mathrm{pmol} / \mathrm{L}(10$ - 19) \\
\hline Flow cytometry & Negative & TSH & $0.31 \mathrm{miu} / \mathrm{L}(0.5-4.0)$ \\
\hline
\end{tabular}

psychosis (about 70\%), hallucinations, cognitive and personality changes. Dyskinesias (especially orofacial), ataxia, seizures and decreased level of consciousness can ensue. Days to weeks later, autonomic instability may occur, manifesting as cardiac arrhythmia, hypotension and hypoventilation, necessitating care in the intensive care unit (ICU).

In order to diagnose this syndrome, anti-NMDA receptor antibodies must be found in CSF. These antibodies can also be detected in serum; to date no case with serum antibodies alone has been noted [1]. The antibody is both highly sensitive and specific with correlating clinical symptoms and titre values; and correspondingly a decrease following treatment. The presence of a lymphocytic pleocytosis is characteristic with either a normal or elevated protein. This was consistent in our patient, noting as well the absence of serum antibodies.

Brain imaging with MRI can be normal in half the patients and may remain unchanged after a severe and 
prolonged course of illness. Electroencephalograms (EEG) show non-specific, slow, and disorganized activity [1]. Brain biopsy is unhelpful. In our patient both her brain MRI and EEG were unremarkable.

Given the paraneoplastic nature of this condition it is not surprising that there is tumour association, present in $60 \%$ of patients, most commonly being an ovarian tumour. Other tumours such as sex-cord stromal tumours, small-cell lung cancer and testicular teratomas can occur but are rare. In some, no tumour can be found [3].

Excision of tumor offers the most clinical benefit in affected patients and as such patients should be screened with MRI, CT Scan and pelvic transvaginal ultrasound [1]. Serological tumour markers are often negative in many patients as demonstrated in our patient.Long-term surveillance is important as clinical manifestations can be delayed up to years as shown in one retrospective study from Japan identifying a tumor 4 - 7 years after the initial diagnosis [3].

Aggressive treatment and a multi-disciplinary approach is vital for this complex syndrome. The main focus is to remove the underlying tumour to lessen antigen burden. In combination with immunotherapy this has been shown to have a good clinical outcome if treated early. There have been no randomized controlled trials to evaluate treatment for anti-NMDA-R encephalitis.

First line of immunotherapy is with corticosteroids (methylprednisolone $1 \mathrm{~g} /$ day for 5 days), intravenous immunoglobulins ( $0.4 \mathrm{~g} / \mathrm{kg}$ for 5 days) or plasma exchange (PLEX). Second-line immunotherapy is with Rituximab $\left(375 \mathrm{mg} / \mathrm{m}^{2}\right.$ every week for 4 weeks) and cyclophosphamide $\left(750 \mathrm{mg} / \mathrm{m}^{2}\right.$ given with first dose of Rituximab followed by monthly cycles of cyclophosphamide for $4-6$ weeks) [1]. The patient was not considered for plasma exchange as she was uncooperative due to the psychosis.

Despite the severity of symptoms and prolonged clinical course, most patients recover if the disorder is recognized and treated early [5]. Overall, the prognosis is good. In one case report, 75\% recovered or had mild deficits, while $18 \%$ remained severely disabled, with $7 \%$ dying as a result of the encephalitis [5].

Factors which affect outcome include disease severity and delay in starting treatment; these have been associated with increased rate of relapses and tumour recurrence. There can be a reversal of order in the course of recovery, for example, becoming agitated and restless again, and then calming as they recover.

For the acute stage of the disease, many patients need to be hospitalized for several months, some requiring intensive care support followed by several months of physical and behavioural rehabilitation. Our patient's length of stay in hospital was 60 days including rehabilitation over a month. She did not require intensive care support.

Risk of relapse can occur after several years in 15\% - 24\% [5], therefore, screening for at least every 2 years is recommended [3]. In one case, series of 360 patients with a reasonable length of follow-up (more than 6 months) the mortality for this condition was $4 \%$ with a median time from disease onset until death of 3.5 months [5].

When thinking of a differential diagnosis, viral encephalitis (HSV-1 and EBV) [6] [7] with other aetiologies such as metabolic, toxic causes, neuroleptic malignant syndrome and serotonin syndrome should be considered.

In viral encephalitis, patients are usually older, have fewer psychiatric and movement disorders, have focal EEG abnormalities of the temporal lobe and a positive HSV PCR in the CSF [8] [9]. Features such as autonomic instability and complex and generalized seizures are uncommon.

The range of abnormal movements, psychiatric symptoms, autonomic features and central hypoventilation, distinguish anti-NMDA receptor encephalitis from other paraneoplastic encephalitis. Paraneoplastic limbic encephalitis is characterized by short-term memory impairment, temporal lobe seizures, and psychiatric symptoms.

Initially, the possibility of serotonin syndrome and neuroleptic malignant syndrome was considered given the features of autonomic instability, an elevated CK and hypereflexia in the setting of antipsychotic use. A viral aetiology was also considered given the prodromal symptoms, fever, confusion and lymphocytic pleocytois. On further testing these possibilities were excluded.

\section{Conclusions}

Anti-NMDAR encephalitis is a recognizable and treatable condition. Overall, patients have good outcomes with aggressive and prompt therapy.

Clinicians must be aware of this condition, especially when evaluating patients with encephalitis since treatment offered in a timely manner can impact outcomes and survival.

Local laboratories should consider developing the anti-NMDA receptor antibody test so that the diagnosis can be confirmed and proper treatment can be instituted early. So far, the test is only available in Queensland. With 
wider pattern recognition of this disease, more diagnoses of anti-NMDA receptor encephalitis are expected in the future.

Overall, the learning points from this case demonstrated the following:

1) The importance of an atypical nature of presentation:

a) Not just psychosis alone, but also autonomic instability, headache and a prodromal illness

b) Importance of lymphocyte pleocytosis, this was the red flag that eventually led us to the diagnosis

c) Psychosis that was a completely treatment-resistant

2) The importance of pre-test probability, i.e. initially the gynaecologists/radiologists did not appreciate the ovarian mass in context of anti-NMDAR encephalitis.

\section{References}

[1] Dalmau, J., Lancaster, E., Martinez-Hernandez, E., Rosenfeld, M.R. and Balice-Gordon, R. (2011) Clinical Experience and Laboratory Investigations in Patients with Anti-NMDAR Encephalitis. The Lancet Neurology, 10, 63.

[2] Florance, N.R., Davis, R.L., Lam, C., et al. (2009) Anti-N-methyl-Daspartate Receptor (NMDAR) Encephalitis in Children and Adolescents. Annals of Neurology, 66, 11-18. http://dx.doi.org/10.1002/ana.21756

[3] Iizuka, T., Sakai, F., Ide, T., et al. (2008) Anti-NMDA Receptor Encephalitis in Japan: Long-Term Outcome without Tumor Removal. Neurology, 70, 504-511. http://dx.doi.org/10.1212/01.wnl.0000278388.90370.c3

[4] Zalel, Y., Piura, B., Elchalal, U., Czernobilsky, B., Antebi, S. and Dgani, R. (1996) Diagnosis and Management of Malignant Germ Cell Ovarian Tumours in Young Females. International Journal of Gynecology \& Obstetrics, 55, 1-10.

[5] Dalmau, J., Gleichman, A.J., Hughes, E.G., et al. (2008) Anti-NMDA-Receptor Encephalitis: Case Series and Analysis of the Effects of Antibodies. The Lancet Neurology, 7, 1091-1098. http://dx.doi.org/10.1016/S1474-4422(08)70224-2

[6] Dalmau, J., Tuzun, E., Wu, H.Y., et al. (2007) Paraneoplastic Anti-N-Methyl-D-aspartate Receptor Encephalitis Associated with ovarian teratoma. Annals of Neurology, 61, 25-36. http://dx.doi.org/10.1002/ana.21050

[7] Glaser, C.A., Honarmand, S., Anderson, L.J., et al. (2006) Beyond Viruses: Clinical Profiles and Etiologies Associated with Encephalitis. Clinical Infectious Diseases, 43, 1565-1577. http://dx.doi.org/10.1086/509330

[8] Redington, J.J. and Tyler, K.L. (2002) Viral Infections of the Nervous System, 2002: Update on Diagnosis and Treatment. Archives of Neurology, 59, 712-718. http://dx.doi.org/10.1001/archneur.59.5.712

[9] Hinson, V.K. and Tyor, W.R. (2001) Update on Viral Encephalitis. Current Opinion in Neurology, 14, 369-374. http://dx.doi.org/10.1097/00019052-200106000-00017 